\title{
PROCESSOS AVALIATIVOS NA EDUCAÇÃO SUPERIOR: OS PLANOS DE ENSINO EM ANÁLISE
}

\author{
PROCEDIMIENTOS EVALUADOS EN LA EDUCACIÓN SUPERIOR: \\ LOS PLANES DE ENSEÑANZA EN ANÁLISIS
}

\author{
EVALUATION PROCESSES IN HIGHER EDUCATION: \\ THE TEACHING PLANS IN ANALYSIS
}

\author{
Taíze dos Santos BATISTTI ${ }^{1}$ \\ Valdete Moser PRETO ${ }^{2}$ \\ Marcia Regina Selpa HEINZLE ${ }^{3}$
}

RESUMO: Analisar os processos avaliativos presentes no plano de ensino de um Curso de Licenciatura em Artes Visuais foi o objetivo geral deste estudo. Para esse fim, realizou-se a recolha de dados por meio da leitura dos planos de ensino de um curso de uma Instituição de Ensino Superior, situada no município de Blumenau, Santa Catarina. Optou-se pela análise documental com base em André e Ludke. Com relação à análise dos dados, dialogamos com o aporte teórico dos seguintes autores: Barbosa, Hernandez, Luckesi, Hoffmann e Zabala. Dentre o principal resultado encontrado, identificamos um número diversificado de instrumentos, que estão em conformidade com os conteúdos procedimentais. Entre os critérios predomina a avaliação de conteúdos procedimentais e atitudinais. Nos objetivos específicos, a ênfase está nos conteúdos conceituais. Os processos avaliativos contidos nos planos de ensino do curso de Artes Visuais permitiram-nos refletir sobre a autonomia dos professores e a avaliação na Educação Superior, que revela aproximações com a perspectiva de avaliação mediadora e a sua função formativa. Compreendemos ainda que os diversos instrumentos avaliativos enfatizam em sua maioria uma relação com as práticas artísticas desenvolvidas no processo de ensino aprendizagem.

PALAVRAS-CHAVE: Processos Avaliativos. Planos de ensino. Artes Visuais. Educação superior.

RESUMEN: Analisar los procesos avaliativos presentes en el plan de enseñanza de la carrera en Artes Visuales fue lo objetivo general del estudio. Para tal fin, se realizó la

\footnotetext{
1 Mestre em Educação pela Universidade Regional de Blumenau (FURB). Integrante do Grupo de Estudos e Pesquisas em Educação Superior (GEPES). Professora de Artes da Rede Municipal de Ensino de Rio do Sul. E-mail: taize1@ @otmail.com

${ }^{2}$ Universidade Regional de Blumenau (FURB), SC - Brasil. Mestranda em Educação. Integrante do Grupo de Estudos e Pesquisas em Educação Superior (GEPES). Coordenadora Pedagógica do SESI, Rio do Sul. E-mail: valdetepreto@ hotmail.com

${ }^{3}$ Universidade Regional de Blumenau (FURB), SC - Brasil. Professora e Pesquisadora no Programa de Pós-Graduação em Educação da Universidade Regional de Blumenau (FURB). Líder do Grupo de Estudos e Pesquisas em Educação Superior (GEPES). Doutora em Educação pela UNICAMP. E-mail: selpamarcia@gmail.com.
} 
recogida de los datos por medio de la lectura de los planes de enseñanza de un curso de una Instituición de Ensino Superior, situada en la ciudad de Blumenau, Santa Catarina. Se elegió la análisis documental con base en André y Ludke. Con relación a la análisis de los datos, hablamos con el aporte teorico de los autores: Barbosa, Hernandez, Luckesi, Hoffmann y Zabala. Entre el principal resultado encontrado, identificamos un número diversificado de instrumentos, que están en conformidad con los contenidos procedimentales. Entre los criterios predomina la evaluación de contenidos procedimentales y actitudinales. En los objetivos específicos, el énfasis está en los contenidos conceptuales. Los procesos evaluadores contenidos en los planes de enseñanza de la carrera de Artes Visuales nos permitieron reflexionar sobre la autonomía de los profesores y la evaluación en la Educación Superior que revela aproximaciones con la perspectiva de evaluación mediadora y su función formativa. Comprendemos también que los diversos instrumentos de evaluación enfatizan en su mayoría una relación con las prácticas artísticas desarrolladas en el proceso de enseñanza aprendizaje.

PALAVRAS-CLAVE: Procesos Avaliativos. Planes de enseñanza. Artes visuales. Educación universitaria.

ABSTRACT: The general objective of this study was to analyze the evaluative processes present in the teaching plan of a Bachelor's Degree in Visual Arts. Therefore, data collection was done by reading the teaching plans of a course of a Higher Education Institution, located in the city of Blumenau, State of Santa Catarina, Brazil. Documentary analysis was based on André and Ludke. In relation to the data analysis, we dialogued with the theoretical contribution of the following authors: Barbosa, Hernandez, Luckesi, Hoffmann and Zabala. Among the main results, we identified a diverse number of instruments, which are in accordance with the procedural contents. Among the criteria, the evaluation of procedural and attitudinal contents predominates. In the specific objectives, the emphasis is on conceptual content. The evaluation processes contained in the teaching plans of the Visual Arts course allowed us to reflect on the autonomy of teachers and the evaluation in Higher Education that reveal approximations with the perspective of mediator evaluation and its formative function. We also understand that the various evaluation instruments emphasize, in their majority, a relation with the artistic practices developed in the process of teaching and learning.

KEYWORDS: Evaluation processes. Teaching plans. Visual arts. Higher education.

\section{Introdução}

Quais os objetivos, instrumentos e critérios avaliativos presentes nos planos de ensino de uma Licenciatura de Artes Visuais? Partimos desta indagação para evidenciar nossa preocupação com os processos de avaliação existentes na educação superior, neste caso específico, o curso de Artes Visuais. Mais do que evidenciar esses elementos, queremos refletir sobre a avaliação na educação superior como elemento aliado aos 
objetivos da aprendizagem, bem como analisar se os instrumentos e critérios de avaliação existentes nestes documentos estão em concordância com os objetivos da aprendizagem.

Este estudo torna-se relevante na medida em que poderá contribuir com a prática avaliativa, e no desenvolvimento do planejamento dos professores da educação superior.

Partimos do pressuposto que existe uma diversidade de elementos teóricos, curriculares, metodológicos e avaliativos, presente nos Projetos Pedagógicos de Cursos. Assim, optamos em analisar os Planos de Ensino, considerando que os mesmos dinamizam o fazer pedagógico. Para analisar os objetivos, instrumentos e critérios avaliativos existentes nos planos de ensino, foi utilizado um aporte teórico a fim de aprofundar relações sobre a avaliação. Neste sentido, foi necessário buscar relações com o ensino da arte, e para isso utilizamos Barbosa (1998); Luckesi (1995), com os fundamentos da avaliação da aprendizagem, Hoffmann (2005), que traz aspectos da avaliação mediadora, Hernandez (1998, 2000, 2005), ao abordar a avaliação em Artes Visuais, e Zabala (1998), que contribui com as definições de conteúdos conceituais, atitudinais e procedimentais. Este texto está organizado da seguinte forma: após a introdução, trazemos a fundamentação com os autores citados anteriormente, e a análise dos dados e as considerações finais a que chegamos com este estudo.

\section{Aprender artes visuais na educação superior: dos objetos à avaliação}

Estudar os processos avaliativos presentes no plano de ensino de um Curso de Licenciatura em Artes Visuais implica, primeiramente, um pensar sobre duas perguntas essenciais: Razões para aprender Artes Visuais? O que aprender em Artes Visuais no contexto da universidade?

Numa atual perspectiva sobre as razões para aprender artes visuais e a sua função dentro do espaço formativo na Educação Superior, existe um consenso entre os estudiosos de que o ensino de arte contribui para ampliar o desenvolvimento cultural e a consciência da cidadania dos seres humanos. De acordo com Barbosa (1998, p. 16), através da arte é possível desenvolver a "[...] percepção e a imaginação, aprender a realidade do meio ambiente, desenvolver a capacidade crítica, permitindo analisar a realidade percebida e desenvolver a criatividade de maneira a mudar a realidade que foi analisada”. Neste sentido, a autora frisa que a Arte Visual tem a imagem como matériaprima e contribui para que os sujeitos se tornem capazes de visualizar a si mesmos, 
permitir-se ver a sua própria localização no mundo e como sentem-se em relação a este mesmo mundo.

A arte, enquanto área do conhecimento, tem um papel fundamental na consciência para a cidadania. Barbosa (1998, p. 17) alerta que não basta apenas incluir as artes no currículo “[...] é também necessário se preocupar como a arte é concebida e ensinada. O conhecimento das artes tem lugar na intersecção: experimentação, decodificação, informação". Portanto, as artes visuais contribuem dando sentido a como os sujeitos produzem e leem as imagens do mundo ao seu redor, fornecendo aos sujeitos uma visão cidadã de si no mundo em que vivem. Deste modo, a subjetividade faz parte dos processos de ensino-aprendizagem em artes visuais. Neste posicionamento sobre a subjetividade, é pertinente pensarmos na nossa posição enquanto educadores. Hernandez (2005, p. 38) ressalta:

Se adotamos este marco, é porque na atualidade, parece-nos que tanto no campo das Artes Visuais, como na educação escolar, estamos buscando uma narrativa que situe seu sentido social em um momento histórico, no qual estamos produzindo profundas transformações nas formas de representação e nas estratégias para investir desde e sobre elas.

Deste modo, concebemos que a partir das mudanças ocorridas na sociedade nos últimos tempos, faz-se pertinente refletir sobre quais são os conteúdos a aprender em Artes Visuais no contexto da Educação Superior? Neste sentido, Hernandez (2005, p. 39) ressalva que os futuros docentes devem assumir-se como "[...] mediadores de formas de fixar a realidade e de posições subjetivas de si mesmos e dos estudantes". Assim, os professores escolhem os conteúdos e direcionam os objetivos de forma a exercer uma postura autônoma para desenvolver os saberes curriculares. Conforme verificamos, existem conteúdos de vários níveis a serem desenvolvidos com os estudantes no âmbito das Artes Visuais. De acordo com as Diretrizes Curriculares Nacionais, os cursos de graduação em Artes Visuais devem desenvolver o perfil para o egresso a partir dos seguintes tópicos de estudos ou de conteúdos interligados:

I - nível básico: estudos de fundamentação teórico-práticos relativos à especificidade da percepção, criação e reflexão sobre o fenômeno visual;

II - nível de desenvolvimento: estudos e processos de interação com outras áreas do conhecimento, tais como filosofia, estética, sociologia, comunicação e teorias do conhecimento, com o objetivo de fazer emergir e amadurecer a linguagem pessoal do formando através da elaboração e execução de seus projetos; III - nível de aprofundamento: 
desenvolvimento do trabalho do formando sob orientação de um professor, buscando vínculos de qualificação técnica e conceitual compatíveis com a realidade mais ampla no contexto da arte. Parágrafo único. Os conteúdos curriculares devem considerar o fenômeno visual a partir de seus processos de instauração, transmissão e recepção, aliando a práxis à reflexão crítico-conceitual e admitindose diferentes aspectos: históricos, educacionais, sociológicos, psicológicos, filosóficos e tecnológicos. (BRASIL, 2009, p. 2)

Como podemos compreender, o documento oficial prevê que são três os níveis de conteúdos, e eles relacionam-se entre si. Portanto, no ensino das Artes Visuais no contexto curricular estão previstos níveis básicos, de desenvolvimento e aprofundamento dos conteúdos.

Partindo destas considerações, temos como pretensão analisar os procedimentos avaliativos a partir de perspectivas e funções de avaliação no processo de ensinoaprendizagem na Educação Superior.

\section{Avaliação: perspectivas e funções}

Apurar questões sobre a avaliação e seus elementos implica refletir sobre os processos de ensino-aprendizagem. Hoffmann (2005) afirma que a avaliação é um meio de aprendizagem e não um fim. A avaliação é parte integrante do processo de ensino e aprendizagem e possibilita a tomada de decisão e a melhoria da qualidade de ensino, podendo servir como instrumento para que o professor tenha condições de saber como está a aprendizagem dos estudantes, como anda sua prática e, partir daí, promover uma recuperação. Desta maneira, pode melhorar sua prática. A autora defende que a avaliação enquanto uma:

Mediação significa encontro, abertura ao diálogo, interação. Uma trajetória de conhecimento percorrida num mesmo tempo e cenário por alunos e professores. Trajetos que se desencontram, por vezes, e se cruzam por outras, mas seguem em frente, na mesma direção. (HOFFMANN, 2005, p. 40, grifo nosso).

Nesta perspectiva, a avaliação mediadora se dá por meio de trocas de experiências, onde os sujeitos aprendem mutuamente e passam a avaliar-se. Nesta direção, Hernandez (1998) ressalva que a avaliação está atrelada ao processo de formação, com o desenvolvimento de competências dos indivíduos. Desta maneira, o 
autor afirma que dentro do processo formativo deve haver um planejamento conjunto sobre as competências que serão avaliadas. Para o autor, a avaliação pode ser: diagnóstica, formativa e acreditativa (HERNANDEZ, 1998). A função diagnóstica parte do que o aluno já sabe da bagagem que constituiu nos processos de ensino e aprendizagem. A avaliação com função formativa procura identificar o nível de evolução no processo de aprendizagem do aluno. A função acreditativa da avaliação procura identificar se o educando alcançou e respondeu aos objetivos esperados. Luckesi (1995 p.43) salienta que a avaliação com a função diagnóstica serve como “[...] instrumento do reconhecimento dos caminhos percorridos e da identificação dos caminhos a serem perseguidos". Assim, o aluno, o professor e a própria instituição podem refletir, reorganizar, reformular, dialogar sobre seu próprio desempenho, sua própria evolução, seu desenvolvimento e sua participação na construção do conhecimento.

No entanto, a avaliação como ação mediadora significa desenvolver um trabalho de reflexão da produção de conhecimento, ou seja: "Refletir a respeito da produção de conhecimento do aluno para encaminha-lo à superação, ao enriquecimento do saber, significa desenvolver uma ação avaliativa mediadora” (HOFFMANN, 2005, p. 41). Deste modo, todo o processo de ensino e aprendizagem torna-se importante e é de fato um processo avaliativo. Com base em Hoffmann (2005, p. 73), avaliar é essencialmente questionar, "[...] é observar e promover experiências educativas que signifiquem provocações intelectuais e significativas no sentido de desenvolvimento do aluno". Como mediador, o professor compreende a avaliação a partir de múltiplas oportunidades. Ele se dispõe a oferecer formas de pensar e buscar o conhecimento com seus estudantes a partir de variadas formas e estratégias. A concepção mediadora oferece oportunidades múltiplas de gerar o conhecimento.

\section{Procedimentos metodológicos}

Investigamos a partir de uma abordagem qualitativa, tendo como finalidade o seguinte objetivo: analisar os objetivos, instrumentos e critérios avaliativos existentes nos planos de ensino do Curso de Artes Visuais de uma Instituição de Ensino Superior de Blumenau, SC. A partir da pesquisa documental, foram analisados os Planos de Ensino dos Cursos de Artes Visuais. A pesquisa a partir de documentos é denominada 
por André e Lüdke (2012 p. 39) como análise documental, e representa, “[...] uma fonte natural de informação. Não é apenas uma fonte de informação contextualizada, mas surge num determinado contexto e fornecem informações sobre esse mesmo contexto". Nesta investigação nos pautamos pela busca de informações referentes aos processos avaliativos existentes nos documentos pertencentes ao curso. Os dados foram solicitados junto ao setor responsável da Universidade. Foram disponibilizadas as matrizes referentes a oito semestres de vigência do curso. Pelo volume de dados optamos por escolher para este estudo um semestre para analisar. Os componentes curriculares do segundo semestre foram: fotografia, TCC I, Escultura I, Estágio em Artes Visuais III e Arte e Tecnologia II.

Identificamos na estrutura dos planos de ensino dos cursos de Artes Visuais as seguintes palavras-chave: objetivos, instrumentos e critérios de avaliação. Organizamos os dados obtidos em quadros seguindo esta estrutura. Como procedimento de análise dos dados optamos pela análise do conteúdo, que é definida como "Um conjunto de instrumentos metodológicos cada vez mais sutis em constante aperfeiçoamento, que se aplicam a 'discursos' (conteúdos e continentes) extremamente diversificados". (BARDIN, 2011, p. 15).

Para tanto, a partir da análise do conteúdo conseguimos estabelecer as categorias de análise. Estas categorias emergiram após a leitura e interpretação dos dados, juntamente com a fundamentação dos autores que são pertinentes às discussões sobre avaliação.

\section{Discussão de dados}

Em função do objetivo proposto, que é: analisar os objetivos, instrumentos e critérios avaliativos presentes nos planos de ensino do Curso de Licenciatura em Artes Visuais de uma Universidade de Blumenau, foi necessário sistematizar os dados em quadros. Analisamos cinco planos de ensino no semestre vigente ao período de realização deste estudo. Neste sentido, atribuímos o conceito de plano de ensino, proposto por Gil (1997, p. 36-37): “O plano de disciplina constitui uma previsão das atividades a serem desenvolvidas ao longo de um ano ou semestre. Constitui, portanto, um marco de referências de ações do professor voltadas ao alcance dos objetivos da disciplina". Deste modo, entendemos o plano como um meio de planejamento que é 
desenvolvido previamente pelo professor. O planejamento, de acordo com Vasconcellos (2000, p. 79, grifo nosso), ocorre:

\begin{abstract}
Enquanto construção-transformação de representações é uma mediação teórica metodológica para a ação, que em função de tal mediação passa a ser consciente e intencional. Tem por finalidade procurar fazer algo vir à tona, fazer acontecer, concretizar e para isto é necessário estabelecer condições objetivas e subjetivas prevendo o desenvolvimento da ação no tempo.
\end{abstract}

Ao analisarmos, os planos observamos a organização de cada professor e as condições estabelecidas em suas disciplinas. De acordo com Gil (1997), não existem modelos rígidos a serem seguidos em um plano de ensino. Pelo contrário, deve servir de roteiro escrito de forma simples e funcional. $\mathrm{Na}$ análise dos dados coletados a partir dos planos, observamos como os professores organizaram as suas escolhas singulares quanto aos objetivos, critérios, instrumentos. A seguir está disposto o quadro com os objetivos específicos das disciplinas analisadas.

Quadro 1: Objetivos específicos dos planos de ensino do curso de artes visuais

\begin{tabular}{|c|c|}
\hline Fotografia & $\begin{array}{l}\text { Conhecer o plano de ensino, as instalações e os equipamentos que serão utilizados na } \\
\text { disciplina. Compreender a história da fotografia, sua formação e seus processos físicos e } \\
\text { químicos. Compreender os tipos e as funções do equipamento fotográfico tradicional, } \\
\text { comparando-o com a tecnologia digital. Praticar a fotografia através de exercício } \\
\text { prático. Aplicar os conceitos abordados. Conhecer os princípios básicos da fotografia } \\
\text { digital e os softwares mais utilizados. Preparar profissionais aptos para atuarem como } \\
\text { professores de Arte em espaços culturais. Avaliar o aprendizado através da apresentação } \\
\text { de seminário sobre um (a) fotógrafo (a) de destaque no cenário nacional das artes. }\end{array}$ \\
\hline Escultura I & $\begin{array}{l}\text { Refletir sobre os conceitos estéticos e artísticos da escultura. Conhecer aspectos } \\
\text { históricos da escultura por meio de artistas e suas obras. Realizar leitura de imagens de } \\
\text { obras escultóricas, revelando características próprias da linguagem, realizar formas } \\
\text { tridimensionais por meio de pesquisa de materiais (gesso, cimento, argila). Conhecer e } \\
\text { explorar técnicas e práticas da escultura (talha, molde, adição e construção) produção } \\
\text { prática de esculturas com base em artistas brasileiros (escultura em gesso + escultura em } \\
\text { concreto celular + relevo em placas) conhecer práticas da escultura voltadas ao ensino } \\
\text { básico. }\end{array}$ \\
\hline $\begin{array}{c}\text { Arte e } \\
\text { tecnologia }\end{array}$ & $\begin{array}{l}\text { Produzir por meio do computador e de softwares adequados (neste caso Corel Draw e } \\
\text { Adobe Photoshop) composições artísticas. Construir material pedagógico em forma de } \\
\text { livro/história em quadrinho infantil para aulas de artes visuais. Conhecer e elaborar um } \\
\text { material pedagógico sobre caricaturistas e designers gráficos brasileiros. Utilizando-se de } \\
\text { tecnologias disponíveis para compreender o processo de digitalização das imagens e seus } \\
\text { mecanismos para criação, conhecer e desenvolver atividades via software Corel Draw - } \\
\text { Corel Photo Paint. Inserir as atividades de artes gráficas no cotidiano escolar da educação } \\
\text { básica facilitando o processo de ensino aprendizagem das artes visuais. Organizar } \\
\text { propostas de atividades práticas por meio do computador em artes visuais na escola. (Ex.: } \\
\text { jogos) }\end{array}$ \\
\hline $\begin{array}{c}\text { Estágio em } \\
\text { Artes } \\
\text { Visuais III }\end{array}$ & $\begin{array}{l}\text { Discutir a proposta do Plano de Ensino para o semestre, visando o esclarecimento de } \\
\text { possíveis dúvidas, complementação ou supressão de Unidades e Subunidades do mesmo. } \\
\text { Analisar e aprovar coletivamente o Cronograma geral da disciplina. Esclarecer possíveis } \\
\text { dúvidas sobre a documentação necessária para o Estágio Curricular em Artes Visuais III. } \\
\text { Preencher devidamente toda a documentação de estágio e entregar na data prevista. - }\end{array}$ \\
\hline
\end{tabular}




\begin{tabular}{|c|c|}
\hline & 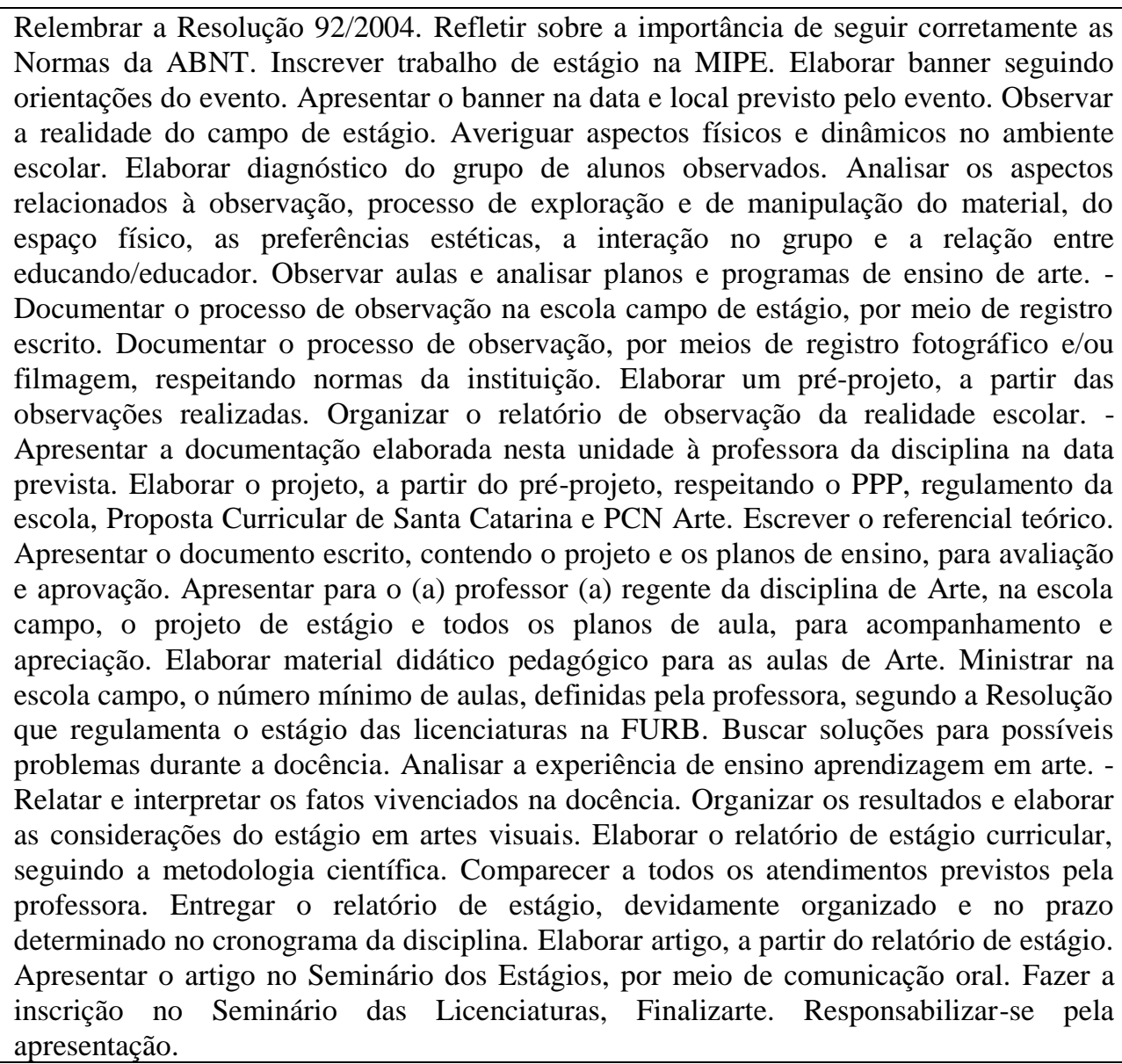 \\
\hline TCC & $\begin{array}{l}\text { Conhecer a proposta do TCC do curso de Artes Visuais contida no Regulamento do } \\
\text { Departamento de Artes. Refletir sobre a importância da pesquisa no processo de } \\
\text { formação docente. Elaborar um conceito próprio de pesquisa, definindo pesquisa como } \\
\text { princípio científico. Reconhecer a função social da pesquisa em Educação. Compreender } \\
\text { as etapas de desenvolvimento da pesquisa, percebendo a necessidade de uma constante } \\
\text { articulação entre as mesmas. Analisar em diferentes TCC's as etapas de pesquisa } \\
\text { estudadas. Conhecer e utilizar na pesquisa as normas atuais da ABNT - Associação } \\
\text { Brasileira de Normas Técnicas. Conhecer as etapas básicas que compõe um projeto de } \\
\text { pesquisa. Elaborar o projeto de pesquisa, considerando todas as suas etapas, resultando na } \\
\text { monografia de conclusão do curso. Fazer a socialização do projeto de pesquisa para a } \\
\text { turma, coletando sugestões e se necessário, fazendo alterações. }\end{array}$ \\
\hline
\end{tabular}

Fonte: Elaboração própria.

Os objetivos específicos, na maioria das vezes, expressam-se principalmente nos verbos: conhecer, compreender, avaliar, refletir, interpretar e apresentar. Isto denota uma relação com os conteúdos conceituais, propostos por Zabala (1998, p. 41): “Os conceitos se referem ao conjunto de fatos, objetos ou símbolos que tem características comuns [...]". Deste modo, os conteúdos conceituais são aqueles que os estudantes precisam ser capazes de aprofundar e compreender de fato como campo de conhecimento. "Uma das características dos conteúdos conceituais é que a aprendizagem quase nunca pode ser considerada acabada, já que sempre existe a 
possibilidade de ampliar ou aprofundar seu conhecimento [...]”. (ZABALA, 1998, p. 43).

Assim, ao avaliar, o professor pode basear-se nas compreensões dos conceitos e não na mera definição, pois há um modo consistente de trazer à tona os conceitos elaborados pelos estudantes. Ao considerar os conceitos dos estudantes do curso de artes visuais, o professor tem a possibilidade de considerar objetivos que vise avaliar também as atitudes dos estudantes frente estes conceitos, como considera Hernandez (2000, p. 162); em Arte, pode ser avaliado: “A participação ativa em todas as atividades [...], as atitudes e manifestações artísticas e seu papel na vida das pessoas." Ou seja, fazse necessário buscar objetivos que colaborem com a avaliação das posturas atitudinais dos estudantes em formação. Esta competência fará parte dos movimentos deste sujeito enquanto profissional docente.

Diante desta primeira análise iniciamos a descrição dos dados contidos nos instrumentos de avaliação. Os instrumentos descritos nos planos dos professores foram organizados no quadro a seguir.

Quadro 2: Instrumentos avaliativos dos planos de ensino do curso de licenciatura em artes visuais

\begin{tabular}{|c|l|}
\hline Disciplinas & \multicolumn{1}{|c|}{ Instrumentos avaliativos } \\
\hline Fotografia & Elaboração de autorretrato, o uso de câmera, exercício com a câmera, seminário. \\
\hline TCCI & $\begin{array}{l}\text { Desenvolvimento do Projeto de Pesquisa: elaboração de projeto e apresentação } \\
\text { oral. }\end{array}$ \\
\hline Escultura I & $\begin{array}{l}\text { Em sala: Apresentação de trabalhos, Produção artística: escultura em gesso + } \\
\text { escultura em concreto celular + relevo em placas }\end{array}$ \\
\hline $\begin{array}{c}\text { Estágio Artes } \\
\text { Visuais III }\end{array}$ & $\begin{array}{l}\text { Diário de bordo } \\
\text { Projeto e planos de aula } \\
\text { Acompanhamento do aluno na escola campo de estágio, utilizando como } \\
\text { instrumento: Fichas de avaliação com respectivos critérios. }\end{array}$ \\
\hline Arte e & $\begin{array}{l}\text { Apresentação de um seminário sobre caricaturistas e designers gráficos brasileiros. } \\
\text { Entrega impressa de um livro ou história em quadrinho infantil Postagem de } \\
\text { trabalhos no ambiente virtual. }\end{array}$ \\
\hline
\end{tabular}

Fonte: Elaboração própria.

Em relação aos instrumentos avaliativos na disciplina Fotografia, foram encontrados: a elaboração de um autorretrato e um Seminário. Na disciplina de TCC I (Trabalho de Conclusão de Curso) foi solicitada a elaboração de um projeto de pesquisa e uma apresentação oral. Para Escultura I foram solicitadas a apresentação de trabalhos em sala e a produção artística de escultura em gesso, mais a escultura em concreto celular e relevo em placas. Em estágio III, os instrumentos usados foram: diário de bordo, projeto e planos de aula, fichas de avaliação. Na disciplina de Arte e Tecnologia 
II a apresentação de um seminário, bem como a entrega impressa de um livro ou história em quadrinho infantil, além da postagem de trabalhos no ambiente virtual.

A leitura e descrição dos instrumentos de avalição possibilitou identificar algumas características e considerações. A partir da autonomia pedagógica, cada professor faz escolhas relacionadas ao seu modo de planejar, mas, sobretudo, oportuniza maneiras próprias de produzir o conhecimento. Portanto, os instrumentos são um meio de propiciar os caminhos para a produção do conhecimento, e mais do que isso, uma oportunidade de o estudante ampliar seus conhecimentos, desenvolver habilidades e atitudes. Luckesi (1995, p. 177), faz a afirmação de que é preciso que tenhamos a capacidade de: "Ter ciência de que, por meio dos instrumentos de avaliação da aprendizagem, estamos solicitando ao educando que manifeste a sua intimidade seu modo de aprender, sua aprendizagem, sua capacidade de raciocinar, de poetizar, de criar estórias $[\ldots] "$.

Assim, constata-se uma diversidade de instrumentos nos planos de ensino, com características teórico-práticas; isto se deve ao fato destas disciplinas fazerem parte do eixo de práticas artísticas, práticas da pesquisa do TCC ou de estágio na Educação Básica. Nos planos de ensino analisados, há ênfases nos instrumentos com práticas artísticas, trabalhos escritos e apresentações orais em seminários. Destacaram-se também outros instrumentos relacionados aos ambientes virtuais de aprendizagem como recurso metodológico. Também evidenciamos a entrega de materiais gráficos pesquisados e produzidos durante o semestre com ênfase na disciplina de estágio. Neste sentido, entendemos que os instrumentos solicitados pelos professores enfatizam em sua maioria os verbos: apresentar, elaborar, desenvolver, organizar. Estes verbos, observados no item objetivos e instrumentos do plano de ensino, fazem relação aos conteúdos procedimentais, propostos por Zabala (1998, p. 207): “Os conteúdos procedimentais implicam saber fazer, e o conhecimento sobre o domínio deste saber fazer só pode ser verificado em situação de aplicação destes conteúdos".

Deste modo, os professores de Artes Visuais, solicitaram na maioria das vezes, práticas artísticas e pedagógicas que demonstrem a capacidade de domínio teórico/prático dos estudantes frente às práticas artísticas e pedagógicas desenvolvidas por eles. Para avaliar a partir dos conteúdos procedimentais é preciso que o professor considere o domínio do conhecimento ao transferi-lo para a prática.

Neste sentido, é preciso avaliar e: "Conhecer até que ponto sabem dialogar, debater, trabalhar em equipe, fazer uma pesquisa bibliográfica, utilizar um instrumento, 
se orientar no espaço, etc. [...]" (HOFFMANN, 2005, p. 106). Como procedem os estudantes diante de variados instrumentos propostos foi uma forma que os professores consideraram importante na avaliação destes sujeitos. Segundo Hoffmann (2005, p. 70), o professor que “[...] propõe atividades diversificadas, propicia a busca do conhecimento a partir de vários agentes de informação, observa, intervém com explicações e novas perguntas, favorece diferentes formas de pensamento [...]". Além disso, é relevante mencionar a perspectiva de avaliação mediadora: "Numa visão mediadora, sempre que os estudos de um curso ou ano letivo estiverem em desenvolvimento, os instrumentos de avaliação serão desencadeadores da continuidade da ação pedagógica [...]”. Deste modo, serão consideradas novas propostas e proposições futuras dos professores e de suas novas ações.

Sendo os instrumentos diversificados, entendemos uma preocupação dos professores em propor em suas formas de avaliar uma proposta em consonância com a ação mediadora, pois eles propõem uma gama variada de instrumentos de avaliação, possibilitando aos estudantes que demonstrem um saber fazer a partir das práticas artísticas. "Para além das atividades diversificadas, a avaliação mediadora exige a organização de experiências educativas diferenciadas. O que significa fazer propostas diferentes aos alunos, articuladas às suas necessidades e possibilidades individuais". (HOFFMANN, 2005, p. 101).

Ao analisar os instrumentos é possível perceber que as descrições preveem experiências variadas com a arte e com a prática pedagógica. Em síntese, podemos dizer que na leitura dos dados contidos no documento conseguimos compreender que há uma diversidade de experiências educativas no âmbito das práticas artísticas. A seguir, partimos para o último item a ser analisado, os critérios de avaliação, que possibilitaram uma posterior análise.

Quadro 3: Critérios avaliativos dos planos de ensino do curso de licenciatura em artes visuais

\begin{tabular}{|c|l|}
\hline Disciplinas & \multicolumn{1}{c|}{ Critérios avaliativos } \\
\hline \multirow{5}{*}{ Fotografia } & $\begin{array}{l}\text { Composição, enquadramento, criatividade; } \\
\text { Domínio e uso adequado do equipamento fotográfico; } \\
\text { Composição, enquadramento, luz, foco, ampliação; } \\
\text { Criatividade, composição, enquadramento e domínio técnico do equipamento fotográfico } \\
\text { e do software de edição de imagens; } \\
\text { Clareza, relevância e pertinência dos aspectos abordados na apresentação, adequação do } \\
\text { uso de recursos audiovisuais. }\end{array}$ \\
\hline \multirow{2}{*}{ TCC I } & $\begin{array}{l}\text { Coerência entre objetivos, conceitos e conteúdos, uso das normas técnicas da ABNT. } \\
\text { Coerência lógica no desenvolvimento de cada etapa da pesquisa, considerando objetivos, } \\
\text { conceitos e conteúdos; }\end{array}$ \\
\hline
\end{tabular}




\begin{tabular}{|c|c|}
\hline & $\begin{array}{l}\text { Atendimentos às normas técnicas da ABNT; cumprimento do prazo de entrega, } \\
\text { Argumentação de defesa frente ao processo de avaliação do projeto. }\end{array}$ \\
\hline Escultura I & $\begin{array}{l}\text { Relevância do conteúdo e clareza na apresentação e dados apresentados; } \\
\text { Relevância do conteúdo } \\
\text { Viagem/pesquisa de campo: relatório (relevância dos dados apresentados) } \\
\text { Domínio técnico e proposta estética. }\end{array}$ \\
\hline Estágio & $\begin{array}{l}\text { 1. Diário de bordo Critérios: anotações realizadas nos atendimentos, considerando o } \\
\text { desenvolvimento e evolução dos alunos. } \\
\text { 2. Ficha de avaliaçãoo do relatório, com respectivos critérios. } \\
\text { 3. Ficha de avaliação do artigo, considerando processo e produto. } \\
\text { 4. Ficha de avaliação da comunicação oral (power point }) \text {. } \\
\text { 5. Ficha de avaliação da apresentação de comunicação oral no Seminário das } \\
\text { Licenciaturas Finalizarte. }\end{array}$ \\
\hline $\begin{array}{c}\text { Arte e } \\
\text { tecnologia }\end{array}$ & $\begin{array}{l}\text { Acesso ao ambiente e realização das tarefas na data prevista. } \\
\text { Organização da galeria de imagens contará a partir do número de imagens que o aluno } \\
\text { colaborou para a construção da mesma. } \\
\text { Nesta Unidade serão considerados os seguintes critérios para avaliação: } \\
\text { - Criatividade, composição equilibrada de acordo com os elementos de linguagem Visual } \\
\text { nas composições digitais e nas composições fotográficas; } \\
\text { - Empenho em descobrir novas ferramentas. } \\
\text { No Ambiente Virtual: } \\
\text { - Postagem dos exercícios práticos no computador referente a esta unidade. } \\
\text { - Assiduidade nas aulas. } \\
\text { - Participação do fórum e outras atividades virtuais no AVA. } \\
\text { Em Sala: } \\
\text { - Criatividade, composição equilibrada de acordo com os elementos de linguagem visual } \\
\text { nas composições digitais e nas composições fotográficas; } \\
\text { - Empenho em descobrir novas ferramentas; } \\
\text { - Organização e manipulação dos softwares e criatividade na proposta pedagógica. }\end{array}$ \\
\hline
\end{tabular}

Fonte: Elaboração própria.

Os professores citam em suas disciplinas diversos critérios de avaliação, de acordo com os instrumentos mencionados. Conforme verificado em Fotografia, foi encontrada a seguinte descrição: composição, enquadramento, criatividade, domínio e uso adequado do equipamento fotográfico; composição, luz, foco, ampliação; criatividade, domínio técnico do equipamento fotográfico e do software de edição de imagens, clareza, relevância e pertinência dos aspectos abordados na apresentação, adequação do uso de recursos audiovisuais. Na disciplina de TCC I (Trabalho de Conclusão de Curso), é possível ler: coerência entre objetivos, conceitos e conteúdos, uso das normas técnicas da ABNT; coerência lógica no desenvolvimento de cada etapa da pesquisa, considerando objetivos, conceitos e conteúdos; atendimentos às normas técnicas da ABNT; cumprimento do prazo de entrega, argumentação de defesa frente ao processo de avaliação do projeto.

Para Escultura I, foram identificados os seguintes critérios: relevância do conteúdo e clareza na apresentação e dados apresentados, relevância do conteúdo, relevância dos dados apresentados e domínio técnico e proposta estética. Em Estágio III são considerados os seguintes critérios de avaliação: criatividade, composição 
equilibrada de acordo com os elementos de linguagem Visual nas composições digitais e nas composições fotográficas, empenho em descobrir novas ferramentas; no Ambiente Virtual: postagem dos exercícios práticos no computador referente a esta unidade, assiduidade nas aulas, participação do fórum e outras atividades virtuais no AVA; em sala: criatividade, composição equilibrada de acordo com os elementos de linguagem visual nas composições digitais e nas composições fotográficas, empenho em descobrir novas ferramentas, organização e manipulação dos softwares e criatividade na proposta pedagógica. Na disciplina de Arte e Tecnologia II houve maior ocorrência de critérios; foram eles: acesso ao ambiente e realização das tarefas na data prevista; organização da galeria de imagens que contará a partir do número de imagens que o aluno colaborou para a construção da mesma. Na unidade da disciplina foram considerados: criatividade, composição equilibrada de acordo com os elementos de linguagem Visual nas composições digitais e nas composições fotográficas, empenho em descobrir novas ferramentas.

No ambiente virtual: postagem dos exercícios práticos no computador; assiduidade nas aulas; participação do fórum e outras. Em sala: criatividade, composição equilibrada de acordo com os elementos de linguagem visual nas composições digitais e nas composições fotográficas; empenho em descobrir novas ferramentas. No ambiente virtual: postagem dos exercícios práticos no computador referente a esta unidade. Assiduidade nas aulas. Participação no fórum e outras atividades virtuais no $\mathrm{AVA}^{4}$. Organização e manipulação dos softwares e criatividade na proposta pedagógica

De acordo com a descrição, foi possível perceber algumas considerações quanto à incidência de critérios que os professores consideraram na redação de seus planos. Quanto à incidência de critérios há alguns destaques: as anotações nas fichas de estágio, a criatividade e o domínio técnico, seguidos de relevância ao conteúdo e uso de normas. Também foi possível notar critérios como a coerência, lógica, assiduidade, participação, empenho, organização e atitudes colaborativas. Verificou-se primeiramente que os critérios estão direcionados aos procedimentos propostos nas disciplinas com práticas artísticas, o que ainda relaciona-se a uma avaliação a partir de conteúdos procedimentais. "Para aprender um conteúdo procedimental é necessário ter uma compreensão do que representa como processo, para que serve, quais são os passos ou

\footnotetext{
${ }^{4}$ Ambiente Virtual de Aprendizagem.
} 
fases que o configuram, etc.” (ZABALA, 1998, p. 207). Em vista disso, também foi possível correlacionar uma avaliação a partir das atitudes dos estudantes frente ao processo de ensino-aprendizagem.

É relevante mencionar que em sua maioria, os professores das disciplinas citaram no decorrer dos planos uma aproximação à avaliação de conteúdos atitudinais, quando citaram a participação, assiduidade, empenho e atitudes colaborativas. Para avaliar a partir dos conteúdos atitudinais faz-se necessário considerar os avanços na aprendizagem a partir da: “[...] observação sistemática de opiniões e das atividades grupais nos debates das assembleias, nas manifestações dentro e fora da aula, nas visitas, passeios e excursões, na distribuição das tarefas e responsabilidades". (ZABALA, 1998, p. 209).

A proposta de considerar as posturas atitudinais se correlaciona aos instrumentos solicitados nas disciplinas, pois elas trazem uma proposta abrangente no modo de avaliar. De acordo com Hoffmann (2005, p. 100): "Quanto mais amplas forem as oportunidades de acompanhar o aluno, em sua interação com o objeto de estudo, agindo sobre ele ou a partir de agentes culturais mediadores [...], maior será o conhecimento das estratégias de aprendizagem desenvolvidas [...]”. Como consequência disso, o estudante se apropriará muito mais dos conceitos previstos nos objetivos específicos concebidos pelos professores.

Deste modo, percebemos que as práticas diversificadas se tornam de fato um meio de avaliar os estudantes a partir dos conteúdos, de suas posturas atitudinais e procedimentais. Portanto, ao analisar esses procedimentos avaliativos, podemos ressaltar que eles propiciam uma avaliação mediadora, pois possibilitam experiências e interações coletivas. Sendo assim:

O processo avaliativo, em sua perspectiva mediadora, destina-se assim, a acompanhar, entender, favorecer a contínua progressão do aluno em termos destas etapas: mobilização, experiência educativa e expressão do conhecimento, alargando o ciclo que se configura a seguir, no sentido de favorecer a abertura do aluno a novas possibilidades. (HOFFMANN, 2005, p. 100).

Traduzindo deste modo uma perspectiva de avaliação mediadora, compreendese uma aproximação aos modos de avaliar previstos nos planos de ensino do curso de Artes Visuais. Em seus planos, os professores preveem uma avaliação por meio de conteúdos conceituais que estão em sua maioria no verbo conhecer, ou seja, estão 
prevendo objetivos de aprendizagem que favorecem o desenvolvimento de novos conhecimentos. Existe uma gama diversificada de instrumentos e critérios oferecidos aos estudantes; assim, eles têm a oportunidade de se mobilizar a partir de novas experiências educativas. "A premissa é oferecer aos alunos muitas e diversificadas oportunidades de pensar, buscar conhecimentos, engajar-se na resolução de problemas, reformular suas hipóteses, comprometendo-se com seus avanços e dificuldades". (HOFFMANN, 2005, P. 73). Sendo assim, foi possível notar que os procedimentos avaliativos estão em consonância com a perspectiva avaliativa mediadora e a função formativa que visa o acompanhamento dos estudantes em seus processos de aprendizagem.

\section{Considerações finais}

Ao analisarmos os objetivos, instrumentos e critérios avaliativos contidos nos planos de ensino do curso de Artes Visuais de uma Universidade de Blumenau, Santa Catarina, concluímos que esta temática abre um amplo campo de investigações. Entretanto, os estudos aqui abordados possibilitam a construção de novos conhecimentos que servirão de subsídios para outras pesquisas. Os dados aqui apresentados evidenciam que cada professor escolhe os objetivos, instrumentos e critérios dos quais fará uso para avaliar o processo de ensino-aprendizagem dos conteúdos desenvolvidos em sua disciplina curricular. Estas escolhas avaliativas se aproximam dos conteúdos conceituais, procedimentais e atitudinais. Na redação dos objetivos específicos, verificamos que predominam os conteúdos conceituais aliados aos processos de aprendizagem dos seus estudantes.

Cada professor considerou objetivos próprios de sua disciplina curricular e esses estão em conformidades com as práticas específicas da área de Artes Visuais, bem como das práticas pedagógicas previstas no estágio e no trabalho de conclusão de curso. Nos instrumentos avaliativos, identificamos que estão em conformidade com os objetivos e estes são diversificados. Porém, destacamos que na descrição dos instrumentos foi possível verificar uma incidência maior de conteúdos procedimentais. E na descrição dos critérios verificou-se uma relação entre os conteúdos atitudinais e procedimentais articuladas. 
Não tivemos a intenção de comparar as formas de avaliar dos professores, mas de analisar de maneira paralela as suas escolhas entre os objetivos, instrumentos e critérios, relacionados aos saberes deste campo. Outro aspecto a ser mencionado é que neste estudo optamos por analisar os planos de ensino apenas de um semestre ao final do curso de Artes Visuais. Portanto, para aprofundar a análise poderíamos ampliar os dados, somando um número maior de disciplinas em diferentes fases do curso. Entendemos que os professores priorizam avaliar as práticas exercidas pelos educandos ao longo das aulas, aproximando-se da função formativa da avaliação, que tem como foco acompanhar o processo evolutivo da aprendizagem. Os elementos contidos na avaliação revelam que os professores se preocupam em evidenciar o aspecto da coletividade no desenvolvimento das atividades. Avaliam as atitudes demonstradas no desenrolar das práticas artísticas. Da mesma forma, os objetivos específicos, bem como seus instrumentos e critérios de avaliação, tiveram os conteúdos procedimentais como um fator predominante nos itens de avaliação. Isto aconteceu, de certa maneira, por ser um semestre com maior número de disciplinas com práticas artísticas específicas e direcionadas ao estágio docente e trabalho de conclusão de curso. O que requer um maior número de conteúdos procedimentais, ou seja, uma relação ao saber/fazer.

Observou-se também que os docentes optaram por atividades mais abertas, em que os estudantes têm maiores condições de expressar os saberes e desenvolverem suas habilidades práticas. Neste sentido, mais do que promover procedimentos ou um saber fazer é preciso que haja mobilização. Cabe aqui ressaltar a afirmação de Hoffmann (2005, p. 180): "Destina-se a avaliação mediadora a conhecer não apenas para compreender, mas para promover ações em beneficio aos educandos, às escolas, e às universidades". Deste modo, os conteúdos conceituais, procedimentais e atitudinais estão presentes na perspectiva de avaliação dos professores do curso de Artes Visuais. Os critérios, instrumentos e objetivos relacionam-se mutuamente aos processos avaliativos baseados numa avaliação mediadora e formativa.

\section{REFERÊNCIAS}

ANDRÉ, Marli; LUDKE, Menga. Pesquisa em educação: abordagens qualitativas. São Paulo: E.P.U., 2012.

BARBOSA, Ana Mae. Tópicos utópicos. Belo Horizonte. Ed. C/Arte, 1998. 
BARDIN, Laurence. Análise de conteúdo. 4.ed. Lisboa: Edições 70, 2011.

BRASIL. Ministério da Educação, Conselho Nacional de Educação. Resolução

CNE/CP 1, de 16 de janeiro de 2009. Institui Diretrizes Curriculares Nacionais do Curso de Graduação em Artes Visuais. Brasília, 2009.

GIL, Antônio Carlos. Metodologia do ensino superior. 3 ed. São Paulo: Atlas, 1997.

HERNANDEZ, Fernando. Transgressão e mudança na educação: os projetos de trabalho. Porto Alegre: Artes Médica, 1998.

HERNANDEZ, Fernando. Cultura visual, mudança educativa e projeto de trabalho. Porto Alegre: Ed Artmed, 2000.

HERNANDEZ, Fernando. A Formação do professor e o ensino das artes visuais. Santa Maria: Ed, UFSM, 2005.

HOFFMANN, Jussara. Avaliar para promover: as setas do caminho. $7^{\mathrm{a}}$ ed. Porto Alegre: Mediação, 2005.

LUCKESI, Cipriano. Avaliação da aprendizagem escolar. 4. ed. São Paulo: Cortez, 1995.

UNIVERSIDADE REGIONAL DE BLUMENAU. Projeto pedagógico do curso de artes visuais, 2015.

VASCONCELLOS, Celso dos S. Planejamento projeto de ensino-aprendizagem e projeto político-pedagógico. Ladermos Libertad-1. $7^{\circ}$ ed. São Paulo, 2000.

ZABALA, Antoni. A prática educativa: como ensinar. Porto Alegre: ARTMED, 1998.

\section{Como referenciar este artigo}

BATISTTI, Taíze dos Santos, et al. Processos avaliativos na Educação Superior: os planos de ensino em análise. Revista Ibero-Americana de Estudos em Educação, Araraquara, v. 12, n. 3, p. 1774-1791, jul-set/2017. Disponível em: <http://dx.doi.org/10.21723/riaee.v12.n.3.2017.8577>. E-ISSN: 1982-5587.

Submetido em: 06/05/2016

Aprovação final em: 19/05/2017 